\title{
Meio ambiente e o ensino de dilatação térmica na perspectiva de um grupo de professores de Física do ensino médio
}

\author{
Environment and the thermal expansion of education in the perspective of a group of high \\ school Physics teachers
}

Lidiane Araújo Matias ${ }^{1}$, Frederico Ayres de Oliveira Neto² e Geison Jader Mello ${ }^{3}$

${ }^{1}$ Licenciada em Física, Secretaria Estadual de Educação do Estado de Mato Grosso, Rondonópolis, MT, Brasil.

2 Doutor em Física, Universidade Federal de Mato Grosso, Cuiabá, MT, Brasil.

${ }^{3}$ Doutor em Física Ambiental, Núcleo de Jaciara, Campus São Vicente, Instituto Federal de Mato Grosso, Jaciara, MT, Brasil.

\begin{abstract}
Resumo
A abordagem teórica da termodinâmica juntamente com sua contextualização proporciona uma melhor compreensão dos fenômenos do dia a dia. Da mesma forma, as conexões da termodinâmica com os processos do meio ambiente proporcionam para os estudantes uma melhor compreensão dos conceitos e uma abordagem interdisciplinar. Dentre os diversos tópicos ensinados em Física no Ensino Médio, a dilatação térmica é um conteúdo no qual os estudantes e professores sem licenciatura em Física apresentam dificuldades. Desta forma, o presente trabalho faz parte de um estudo sobre o ensino de dilatação térmica, tendo como principal objetivo conhecer a perspectiva de um grupo de professores de física sobre o assunto, possibilitando a compreensão de quais conceitos relacionados a esse tema que mais apresentam problemas de ensino e aprendizagem. Para tanto, foi aplicado um questionário a um grupo formado por cinco professores de física, com o objetivo de conhecer a perspectiva desses professores sobre o ensino, levando em consideração que o ensino de física deve tornar os estudantes capazes de entender, participar e intervir nas situações que o cercam.
\end{abstract}

Palavras-chave: Ensino de física. Dilatação térmica. Professores.

\begin{abstract}
The theoretical approach of thermodynamics along with its context provides a better understanding of the phenomena of everyday life. Similarly, the connections with the thermodynamic processes environment for students provide a better understanding of the concepts and an interdisciplinary approach. Among the various topics taught in physics in high school, the thermal expansion is a content in which students and teachers with no degree in physics present difficulties. Thus, this work is part of a study on the teaching of thermal expansion, having as main objective to know the perspective of a group of physics teachers on the teaching of Thermal Expansion, enabling the understanding of which concepts related to this topic have more problems in teaching and learning in school. For this purpose, a questionnaire was administered to five teachers of physics, which contributed to meet the perspective of these teachers on the teaching of physics. The education in physics should make students able to understand, participate and intervene in situations that surround them. For this, the teacher should seek to foster students to learning situations where they can make the association between scientific knowledge and knowledge they already possess, being able to differentiate formal from informal knowledge.
\end{abstract}

Keywords: Teaching physics. Thermal expansion. Teachers. 


\section{Introdução}

Ao estudar a Física Térmica, muitas vezes os estudantes não conseguem separar o conhecimento informal do formal sobre os conceitos relacionados a esse ramo da Física, o que dificulta a construção do conhecimento científico. O ensino de Física inicia-se no ensino fundamental e é mais aprofundado no ensino médio. Mesmo assim, depois de estudar no mínimo quatro anos a Física, os estudantes podem não aprender significativamente os conteúdos e sair das escolas com dúvidas sobre o papel da Física em suas vidas (MOREIRA, 1999). Isso ocorre porque a maioria dos estudantes egressos das escolas pode ter um conceito pré-concebido que a Física se restringe apenas a cálculos matemáticos. No entanto, de acordo com os Parâmetros Curriculares Nacionais para o Ensino Médio (PCNEM) (BRASIL, 2000), os estudantes de Física deverão concluir a educação básica sendo capazes de comunicar-se em torno do saber científico e saber representar, compreender e investigar situações do mundo físico.

O estudo da termodinâmica pode desenvolver competências para compreender o meio ambiente e lidar com as variações climáticas tal qual o agravo do efeito estufa, as alterações na camada de ozônio e as inversões térmicas, possibilitando elementos para avaliar a ação antrópica e a sobrevivência humana diante dessas variações (MELLO et al., 2012). Compreende-se ainda que, em todos os processos que ocorrem na natureza e nas técnicas, o calor está direta ou indiretamente presente (BRASIL, 2002, p. 73). Diante dessas aplicações dos conceitos da termodinâmica no dia a dia enfatizase que:

Os termos "temperatura" e "calor" costumam ser usados como sinônimos na linguagem cotidiana. Na literatura científica, contudo, estes termos têm significados distintos. A compreensão destes termos, e seus processos em termodinâmica, constituem uma parte indispensável dos fundamentos da física, da química e da biologia, e sua aplicação é indispensável em Física Ambiental (ARRUDA, 2009, p. 07).

De acordo com as Orientações Educacionais Complementares aos Parâmetros Curriculares Nacionais PCN+ (BRASIL, 2002) menos ênfase deve ser dada, por exemplo, às escalas termométricas, e mais atenção aos aspectos propriamente termodinâmicos, envolvendo o funcionamento de máquinas térmicas, o próprio conceito de calor e modelos explicativos sobre seu trânsito na matéria, seja no aspecto macroscópico ou microscópico.

Ainda nessa perspectiva, para que haja uma aproximação entre a física e o cotidiano dos estudantes é preciso pensar na Física voltada para a formação do cidadão contemporâneo, para que seja capaz de compreender, intervir e participar da realidade que o cerca (BRASIL, 2002). É necessário buscar sempre uma aprendizagem significativa, a qual é denominada por David Ausubel como a organização e integração do material na estrutura cognitiva do aprendiz (MOREIRA, 1999). A aprendizagem significativa baseia-se na idéia de que um novo conhecimento é assimilado quando ele é relacionado a um conhecimento já existente. Sobre a aprendizagem significativa os PCNEM (BRASIL, 2000, p. 22) afirmam que:

A aprendizagem significativa pressupõe a existência de um referencial que permita aos estudantes identificar e se identificar com as questões propostas. Essa postura não implica permanecer apenas no nível de conhecimento que é dado pelo contexto mais imediato, nem muito menos pelo senso comum, mas visa a gerar a capacidade de compreender e intervir na realidade, numa perspectiva autônoma e desalienante.

De acordo com MOREIRA (2000), nessa época de tantas transformações a aprendizagem deve ser não só significativa, mas também crítica, caracterizando-se pela interação entre o novo conhecimento e o conhecimento prévio. De acordo com esse tipo de aprendizagem, o aprendiz não é um receptor passivo, permitindo que faça parte de sua cultura e, ao mesmo tempo, esteja fora dela. E, ainda, MOREIRA (2000, p. 6) afirma que:

É através da aprendizagem significativa crítica que o estudante poderá fazer parte de sua cultura e, ao mesmo tempo, não ser subjugado por ela, por seus ritos, mitos e ideologias. É através dessa aprendizagem que ele poderá lidar construtivamente com a mudança sem deixar-se dominar por ela, manejar a informação sem 
sentir-se impotente frente a sua grande disponibilidade e velocidade de fluxo, usufruir e desenvolver a tecnologia sem tornar-se tecnófilo. Por meio dela, poderá trabalhar com a incerteza, a relatividade, a nãocausalidade, a probabilidade, a não-dicotomização das diferenças, com a idéia de que o conhecimento é construção (ou invenção) nossa, que apenas representamos o mundo e nunca o captamos diretamente.

Sobre os conhecimentos prévios, VILLATORRE et al (2009, p.39) afirmam que "é importante que o professor, no planejamento de suas aulas, não desconsidere a existência desses conhecimentos prévios dos estudantes". Segundo BEN-DOV (1996, p. 46), o ensino de física no ensino médio "é, em grande parte, dedicado à mecânica newtoniana" e somente no século XIX surgiu "uma nova abordagem científica" resultante do "estudo dos fenômenos ligados ao calor" e "fundada em princípios gerais que permitem estudar sistemas em sua totalidade".

Nesse contexto, se faz necessário pensar e repensar o processo de ensino de Física, para que possamos propiciar aos estudantes situações de aprendizagem, buscando fornecer-lhes condições para que façam essa associação com o conhecimento que eles já possuem, mas que saibam diferenciar o conhecimento formal do informal, de forma que o ensino de Física contribua influenciando positivamente na forma dos estudantes pensarem e agirem.

Vivemos na chamada sociedade do conhecimento, a qual tem afetado diretamente o universo escolar e exigido do professor uma nova postura, o qual, de acordo com FELDMANN (2009, p. 75), "vê-se impelido a rever sua atuação, suas responsabilidades e seus processos de formação e de ação". Ainda, FELDMANN (2009, p. 76) afirma que:

[...] os professores, em suas ações educativas, lidam com a apropriação do conhecimento sistematizado, os significados, a cultura, a construção dos próprios saberes escolares e a dinâmica da própria organização do contexto escolar.

As transformações aceleradas pelas quais a sociedade está passando, exigem um novo modelo de ensino centrado no estudante e que valorize os conhecimentos prévios que ele possui, utilizando-os para criar situações de aprendizagem. Dessa forma, o professor precisa rever seu modo de ensinar e deixar totalmente de lado o papel de transmissor de conhecimentos prontos e acabados, para desempenhar o papel de mediador do processo de ensino e aprendizagem. No ensino de física, essa nova postura do professor é essencial para que a aprendizagem dos conceitos ocorra de forma significativa crítica. Caso contrário, o ensino de física poderá ser resumido a apenas transmissão de conceitos prontos e a repetição de cálculos matemáticos.

Em termodinâmica, o ensino de dilatação térmica envolve cálculos matemáticos e fórmulas, os quais se não forem trabalhados juntamente com a teoria e associados ao cotidiano dos estudantes, podem se tornar um método de ensino mecânico e sem sentido algum para os estudantes. Assim, conhecer a perspectiva de um grupo de professores sobre o ensino de dilatação térmica pode fornecer subsídios para detectar paradigmas relacionados ao ensino e a aprendizagem de física.

Desta maneira, como plano de fundo para uma futura abordagem ambiental, o objetivo deste trabalho foi a investigação da perspectiva de um grupo de professores do ensino médio relacionada aos métodos de ensino aplicados pelos educadores quanto ao conteúdo Dilatação Térmica em aulas de Física.

\section{Material e Métodos}

O presente trabalho objetiva investigar o ensino de Física, em específico o ensino de Dilatação Térmica. Dessa forma, trata-se de uma investigação qualitativa, a qual segundo BOGDAN \& BIKLEN (1994, p. 47):

[...] envolve pegar nos objetos e acontecimentos e levá-los ao instrumento sensível da sua mente de modo a discernir o seu valor como dados. Significa aperceber-se da razão por que os objetos foram produzidos e como isso afeta a sua forma bem como a informação potencial daquilo que está a estudar. Também envolve saber quando descartar certos conjuntos de dados como sendo de valor duvidoso e quando os manter. 
Segundo PRODAV \& FREITAS (2013), ainda podemos classificar esta pesquisa como explicativa, bibliográfica e de levantamento. Explicativa porque procura identificar os fatores que influenciam no ensino de dilatação térmica no ensino médio de acordo com a perspectiva de um grupo de professores; com traços de uma pesquisa bibliográfica porque parte desta pesquisa iniciou-se com a revisão da literatura existente; e de levantamento porque propõe a interrogação a professores de Física.

Neste trabalho, o objeto de estudo (ensino de Dilatação Térmica) foi investigado junto a um grupo de professores de Física do ensino médio, sendo utilizado como instrumento de coleta de dados um questionário destinado a esses educadores, assim como segue abaixo:

Na primeira parte do questionário (bloco 1)os dados pessoais e sobre atuação profissional foram levantados a partir das seguintes questões:

Sexo: ( ) Feminino ( ) Masculino. Idade:

( ) Graduação. Em que área e ano de conclusão.

( ) Especialização. Em que área e ano de conclusão.

( ) Mestrado. Em que área e ano de conclusão.

( ) Doutorado. Em que área e ano de conclusão.

Escola onde trabalha:

Professor efetivo ( ) ou Professor contratado ( )

Para quais séries leciona:

Quais disciplinas ministra:

Há quantos anos você trabalha como professor?

Há quanto tempo você trabalha como professor de Física?

Qual é a sua jornada de trabalho semanal?

Na segunda parte do questionário (bloco 2) foram feitas as questões mais específicas sobre o Ensino de Dilatação Térmica:

a) Em qual bimestre em que você trabalha dilatação térmica?

b) Quais conteúdos de dilatação térmica você trabalha?

c) Qual metodologia de ensino você utiliza para trabalhar esse conteúdo? E quais materiais você utiliza?

d) Qual parte do estudo da dilatação térmica você acha mais difícil de trabalhar no ensino médio? Justifique.

e) Qual parte do estudo da dilatação térmica você acha mais fácil de trabalhar no ensino médio? Justifique.

f) Na sua opinião, qual a maior dificuldade dos estudantes em aprender dilatação térmica? O que você acha que justifica essa dificuldade dos estudantes?

g) Qual livro didático você adota?

h) Qual o conteúdo de Física que você acha mais complicado de ensinar no ensino médio? Por quê?

Os sujeitos desta pesquisa foram escolhidos aleatoriamente, de acordo com os contatos dos pesquisadores, sendo que o questionário foi enviado por e-mail para inúmeros professores, mas apenas cinco responderam ao questionário. A escolha de realizar o contato com os professores por email ocorreu pelo fato de ser um meio de comunicação rápido e que possibilita entrar em contato com o acesso a pessoas de diferentes lugares. Ao analisar as respostas dos professores usamos nomes fictícios para manter o anonimato dos sujeitos da pesquisa. O número reduzido de professores que respondeu ao questionário (espaço amostral) não compromete a pesquisa, uma vez que o foco não é estatístico, mas na perspectiva individual, ou seja, nos paradigmas de cada docente. 


\section{Resultados e Discussão}

Como o ensino de Dilatação Térmica figura nosso objeto de estudo, aplicamos um questionário destinado a um grupo de professores de Física do ensino médio em setembro de 2013, com o intuito de investigar o ensino de Dilatação Térmica na perspectiva desses professores. O questionário é composto por dois blocos:

Bloco 1. Dados Pessoais que apresenta 13 perguntas sobre o sexo, idade, formação e atuação profissional;

Bloco 2. Sobre o Ensino de Dilatação Térmica que apresenta 08 perguntas dissertativas sobre o ensino de dilatação térmica no ensino médio; totalizando 21 perguntas.

O questionário foi aplicado a 20 professores, sendo que 05 devolveram o questionário respondido até outubro de 2013.

No bloco 1 (dados pessoais), verificamos que de cinco professores, três são do sexo feminino e dois do sexo masculino. Em relação à idade, observamos que varia entre 27 e 46 anos, sendo que quatro concentram-se na faixa etária entre 27 e 32 anos e um tem 46 anos.

No que se refere à formação acadêmica, verificamos que três são graduados em Matemática, um tem graduação em Biologia e em Química e apenas um não é graduado na área de exatas, mas em Geografia. Todos concluíram a graduação entre 2002 e 2008. Em relação a pós graduação, três são especialistas e um é mestre.

Quanto às disciplinas ministradas pelos professores foram citadas: Matemática, Química, Física, Sociologia e Filosofia no Ensino Médio. Apenas dois atuam somente em matemática e Física; os demais trabalham mais de duas disciplinas.

O tempo de trabalho como professor varia entre 3 e 17 anos de docência. Já a experiência profissional como professor de Física varia entre um semestre e dezesseis anos. Três professores são efetivos no Estado e dois são contratados da rede estadual de ensino. Em relação à carga horária de trabalho dos professores, um trabalha 24 horas por semana, três trabalham em torno de 35 horas e um trabalha 60 horas.

No bloco 2 (Sobre o Ensino de Dilatação Térmica), dentre os cinco professores, apenas três trabalham Dilatação Térmica. Destes, dois afirmaram trabalhar os conceitos de dilatação linear, superficial e volumétrica, e um afirmou só trabalhar a dilatação linear. No que se refere às estratégias de ensino, os três afirmaram realizar aulas expositivas com o uso de quadro e giz, sendo que um trabalha com a resolução de problemas, um também utiliza vídeos da internet e outro utiliza a experimentação em sala de aula. GASPAR (2014) afirma que realizar atividades experimentais no ensino de Ciências, em particular nas aulas de Física, é fundamental para a aprendizagem de conceitos científicos, de modo que observa-se aqui uma necessidade de ampliação dessas atividades.

Em relação aos conceitos de Dilatação Térmica que os professores consideram mais difíceis de trabalhar no Ensino Médio, dentre os que trabalham esse tema, dois afirmaram ser os cálculos matemáticos para resolver a situações problemas e outro afirmou ser a parte teórica. Já em relação à parte mais fácil, um afirma ser a dilatação linear, por haver vários exemplos no cotidiano dos estudantes; um acha mais fácil trabalhar a parte de cálculos, pois a sua área de formação é a matemática; já outro, apesar de ser matemático afirma que é mais fácil ensinar a parte conceitual devido aos exemplos.

Dentre os três professores que trabalham a Dilatação Térmica, dois afirmaram que a maior dificuldade dos estudantes em aprender os conceitos relacionados a esse tema está relacionada com a realização dos cálculos matemáticos e apenas um citou a compreensão da linguagem Física.

Um dos professores não adota livro didático, pois trabalha com CEJA (Centro de Educação de Jovens e Adultos), o qual não utiliza livros didáticos, e os demais adotam o livro "Física e Realidade", dos autores Aurélio Gonçalves Filho e Carlos Toscano. Além do livro didático, os materiais mais utilizados pelos professores são data-show, vídeos, quadro e giz.

Sobre o conteúdo de Física mais complicado de ensinar no Ensino Médio, dois professores afirmaram ser os conteúdos que envolvem cálculos matemáticos e um afirmou ser a Eletricidade, devido à grande quantidade de teoria. CARVALHO JUNIOR (2011) afirma que o ensino de ciências 
tem apresentado, nas últimas décadas, um notável progresso com relação à necessidade de se dar ouvidos aos estudantes, percebendo suas motivações pessoais, seus conhecimentos prévios, sua relação com o saber e suas formas peculiares de construção do saber, de forma que ações nestas perspectivas poderiam contribuir com a superação dos problemas acima citados.

Ao analisar as respostas obtidas na pesquisa com os professores, foi possível perceber que os entrevistados transpareceram que há carência em professores formados em Física, o que os levou a assumir essa área mesmo sem a formação específica. $\mathrm{O}$ número reduzido de professores que responderam aos questionários não nos permite inferir absolutamente nada a respeito, mas sugere que seja feito um levantamento da formação específica dos professores que lecionam Física na região. Todos os professores deixaram claro que o fato de não serem formados em Física os leva a refletir sobre o comprometimento do ensino e da aprendizagem dos conceitos de Física. O professor formado em Matemática indicou que se sente mais confortável em trabalhar a Física utilizando cálculos matemáticos em suas aulas, enquanto os demais, formados em outras áreas, trabalham mais os conceitos, a teoria.

Para MUELLER et al. (2012), cada professor que ensina imprime formas particulares, inclusive metodológicas, que irão definir as suas estratégias para que o aprendizado seja, ou não, alcançado. Isto corrobora a compreensão das diferentes concepções que os professores apresentaram quanto ao ensino de Física. Possivelmente se os professores entrevistados tivessem tido uma formação mais interdisciplinar, na área das Ciências Naturais, com suas especificidades, seu embasamento teórico e suas metodologias, isto contribuiria para o êxito nas atividades de ensino (Mello et al., 2012).

Outro fato observado é que a experimentação ainda é pouco utilizada pelos professores entrevistados. Segundo eles isso ocorre devido à falta de estrutura nas escolas públicas e à falta de conhecimento dos professores que não são formados em Física. Além disso, percebemos que a maior dificuldade observada pelos professores está no fato de alguns conceitos da Física exigirem dos estudantes um conhecimento de cálculos matemáticos e o raciocínio lógico, tornando-os mais difíceis de trabalhar.

\section{Conclusões}

Na perspectiva de um futuro ensino de Física voltado à temática ambiental, verificou-se que, para os professores entrevistados, o ensino de Dilatação Térmica restringe-se em sua maior parte ao ensino de à dilatação linear, superficial e volumétrica, sendo explorado mais o aspecto matemático para o docente com formação em Matemática e, em alguns casos, só é trabalhada a dilatação linear devido aos outros tipos de dilatação exigirem mais conhecimentos matemáticos por parte do próprio professor. $\mathrm{O}$ fato de nenhum dos entrevistados ser formado em Física pode ser um fator decisivo na escolha do método de ensino no conteúdo específico de dilatação térmica.

Com o levantamento da formação acadêmica e profissional ficou claro que os professores assumiram as aulas de Física devido à falta de professores formados na área, os quais, em princípio, estariam preparados para trabalhar não só a parte teórica, ou só parte de cálculos, mas o todo da linguagem Física, além de buscar propiciar situações em que os estudantes sejam construtores do conhecimento e possam fazer a relação entre o conhecimento formal e informal, no intuito de compreender a linguagem científica.

\section{Agradecimentos}

À Coordenação de Aperfeiçoamento de Pessoal de Nível Superior (CAPES) pelo subsídio através do Programa de Consolidação das Licenciaturas (PRODOCENCIA) Edital 019/2013, processo № 113.657, e do Programa Institucional de Bolsa de Iniciação à Docência (PIBID) Edital № 061/2013, processo № 128.570, IFMT/Campus São Vicente/Sub Projeto Ciências. 


\section{Referências}

ARRUDA, P. H. Z. Aplicações dos fundamentos da Teoria da Aprendizagem Significativa Crítica como instrumentos facilitadores do ensino de termodinâmica em Física Ambiental. Cuiabá, 2009. 100f. Dissertação (Mestrado) - Pós-Graduação em Física Ambiental, Universidade Federal de Mato Grosso.

BEN-DOV, Y. Convite à Física. Traduzido por Maria Luiza X. de A. Borges. Rio de Janeiro: Jorge Zahar Ed., 1996. Tradução de: Invitation à la physique.

BOGDAN, R. C.; BIKLEN, S. K. Investigação Qualitativa em Educação: uma introdução à teoria e aos métodos. Porto - Portugal: Porto Editora, 1994.

BRASIL. Secretaria de Educação Média e Tecnológica. Parâmetros Curriculares Nacionais para o Ensino Médio. Ciências da Natureza, Matemática e suas Tecnologias. Brasília: MEC, 2000.

BRASIL. Secretaria de Educação Média e Tecnológica. PCN+ Ensino Médio: Orientações Educacionais Complementares aos Parâmetros Curriculares Nacionais. Brasília: MEC, 2002.

CARVALHO JUNIOR, G. D. Aula de Física: do planejamento à avaliação. 1. ed. São Paulo: Editora Livraria da Física, 2011.

FELDMANN, M. G. Formação de professores e cotidiano escolar. In: FELDMANN, Marina Graziela (org.). Formação de professores e escola na contemporaneidade. São Paulo: Editora Senac, 2009.

GASPAR, A. Atividades experimentais no ensino de Física: uma nova visão baseada na teoria de Vigotski. 1. ed. São Paulo: Editora Livraria da Física, 2014.

MELLO, G. J. ; SANTOS, V. M. P. ; PAZ, R. C. R. . Física ambiental e educação do campo: experiência em ensino significativo na Amazônia Legal. Revista Pedagogia em Foco, v. 7, p. 126-144, 2012.

MOREIRA, M. A. Aprendizagem Significativa Crítica. Versão revisada e estendida de conferencia proferida no III Encontro Internacional sobre Aprendizagem Significativa, Lisboa, 2000. Publicada nas Atas desse Encontro, pág. 33-45, com o título original de Aprendizagem significativa subversiva.

MOREIRA, M. A. Teorias da Aprendizagem. São Paulo: EPU, 1999.

MUELLER, E. R.; MELLO, G. J.; OLIVEIRA, V. S. Ensino de ciências e matemática na Amazônia Legal: o processo de definição dos conceitos da abordagem na educação do campo. Universitas Humanas, v. 9, n. 1, p. 31-40, 2012.

PRODAV, C. C.; FREITAS, E. C. Metodologia do Trabalho Científico: Métodos e Técnicas da Pesquisa e do Trabalho Acadêmico. 2ª edição. Novo Hamburgo, RS: FEEVALE, 2013.

VILLATORRE, A. M.; HIGA, I.; TYCHANOWICZ, S. D. Didática e Avaliação em Física. São Paulo: Saraiva, 2009. 